\title{
COMEntários sOBRE A PALESTRA "NovAS PERSPECTIVAS NO TRATAMENTO DO CÂNCER DE MAMA"
}

\section{Carlos Vinicius Pereira Leite}

a Auxiliar de Ensino da Cadeira de Ginecologia e

Obstetrícia e Coordenador do Serviço de Mastologia do Hospital de Ensino Alcides Carneiro,

Faculdade de Medicina de Petrópolis,

Av. Barão do Rio Branco, 1003, Centro, Petrópolis, RJ, 25.680-120, Petrópolis (RJ), Brasil.

E-mail: carvin.leite@gmail.com

\section{Resumo}

A palestra "Novas perspectivas no tratamento do câncer de mama", apresentada por Mauricio Augusto Silva Magalhães Costa durante a segunda edição da Academia na Serra II, foi norteada por sua experiência em câncer de mama (CM) ao longo de 40 anos de atividades tratando a doença, descrevendo a sua importância para a saúde pública, a evolução do tratamento cirúrgico, e os progressos das opçóes terapêuticas disponível na atualidade. A detecção oportuna, o diagnóstico preciso, o tratamento personalizado, e o acesso ao Sistema de Saúde e educação são pontos fundamentais que quebram as barreiras que dificultam o sucesso na abordagem do CM.

\author{
Palavras chave \\ Câncer de mama, prevenção, diagnóstico \\ oportuno, tratamento
}

\section{Abstract}

The lecture "New perspectives in the treatment of breast cancer", presented by Mauricio Augusto Silva Magalhães Costa during the second edition of the Symposium A Academia na Serra II, was guided by his experience in breast cancer (CM) over 40 years of activities treating the disease, describing its importance for public health, the evolution of surgical treatment, and the progress of therapeutic options available today. Early detection, accurate diagnosis, personalized treatment, and access to the Health System and to education are fundamental points that break the barriers that hinder success in approaching the CM.

\section{Keywords}

Breast cancer, prevention, timely diagnosis, treatment 
Mauricio Costa iniciou a sua palestra "Novas perspectivas no tratamento do câncer de mama" no Simpósio da Academia na Serra II apresentando os dados do CM globalmente e posicionando a doença como o principal câncer em mulheres no mundo. Para o ano de 2018, a estimativa para o Brasil foi de 59.700 novos casos, com risco estimado de 56,33/100.000 mulheres (Instituto Nacional de Câncer, INCA), sendo o risco estimado diferente em distintas regióes brasileiras em função do desenvolvimento observado nelas.

$\mathrm{O}$ intervalo entre o diagnóstico e a cirurgia afeta diretamente a sobrevida das pacientes, sendo um aumento de mortalidade pela doença observado quando esse prazo alcança ou ultrapassa os 60 dias, de onde a importância de reduzir o tempo de espera para a cirurgia ${ }^{1}$. Essa reflexão levou a Lei dos 60 dias, que dispóe sobre o direito do paciente com neoplasia maligna de se submeter ao primeiro tratamento no Sistema Único de Saúde (SUS) no prazo de até 60 (sessenta) dias contados a partir do dia em que for firmado o diagnostico em laudo patológico ou em prazo menor.

A detecção oportuna, o diagnostico preciso, o tratamento personalizado, o acesso ao Sistema de Saúde e a educação são estratégias para o controle do CM. A melhora das imagens de mamografia, ultrassonografia e ressonância tem propiciado diagnóstico progressivamente mais precisos e mais cedo no curso da doença. São detectadas lesôes na fase subclínica, que através de punçóes guiadas, permitem o diagnóstico, facilitando o planejamento terapêutico em abordagem única.

Concomitantemente à melhora da qualidade das imagens, o tratamento cirúrgico também evoluiu. Atualmente $60 \%$ das pacientes são tratadas por cirurgias conservadoras. As que não são elegíveis para o tratamento conservador tem opção de reconstruçáo imediata, respeitando uma serie de critérios, para tentar reconstruir sua estética corporal. Maurício Costa lembrou que a mastectomia radical, apesar de queda significativa nas taxas de recorrência local, não foi suficiente para a resolução de todos os casos e que um significado número de mortes causados pela doença continuou a ser observado. Levantou a importância do tratamento sistêmico no controle do CM. A partir desse conceito, o tratamento cirúrgico modifica, com mais cirurgias conservadoras, mais informaçóes sobre o tumor (não só o tipo histológico e grau, mas os dados de imuno-histoquímica e assinatura genética) com melhora significativa da sobrevida.

Um marco importante na evolução do tratamento cirúrgico foi a possibilidade de se evitar o esvaziamento axilar com o surgimento do conceito do linfonodo sentinela que solidificou a possibilidade de evitar a dissecção axilar para todos os casos, com 
menos morbidade para as pacientes sem impacto na sobrevida.

A cirurgia oncoplástica, que aplica princípios de cirurgia oncológica e plástica reconstrutora para o tratamento de mulheres com CM tem como princípios gerais: reduzir a taxa de mastectomias, reduzir a taxa de reoperaçóes e melhorar a qualidade do resultado estético quando a cirurgia conservadora não é possível.

Costa abordou a radioterapia que evoluiu com novos aparelhos como o INTRABEAM para radioterapia intraoperatorio diminuindo o tempo e o MAMMOSITE, método avançado de irradiação parcial da mama em alta dose.

Além do tratamento local, foi destacada ainda a necessidade de se oferecer um tratamento sistêmico para as pacientes. $\mathrm{O}$ conceito da medicina personalizada em CM visa qualificar os benefícios do tratamento, avaliar risco, toxicidade, risco de recidiva e morte para buscar o controle local e sistêmico mais efetivos e com menos efeitos adversos.

A distinção, através do perfil imunohistoquímico, em subtipos luminais $\mathrm{A}$, luminais B e Her2 superexpresso e triplo negativo, cada um com comportamento e prognósticos distintos, permite orientar um tratamento mais adequado e personalizado. Recentemente com um melhor entendimento da estrutura de sequenciamento do DNA humano surgiram os testes genéticos (Oncotype DX, Mammaprint, Prosigna) que des- crevem o prognóstico do risco de recidiva e a necessidade ou não do tratamento quimioterápico em pacientes positivos para a presença de tumores receptores de estrógeno.

Ressaltou-se também que a incorporação do rastreio associado a essa terapia adjuvante é fundamental para melhorar os resultados levando à diminuição da mortalidade do CM.

Evidenciou-se o "efeito Angelina Jolie", a cirurgia redutora de risco e a Mastectomia profilática bilateral. A definição de família de alto risco para o desenvolvimento de CM e/ou ovário tem critérios bem estabelecidos. Portadoras de mutaçôes BRCA 1 E BRCA 2 tem um risco de 50-85\% de desenvolver o câncer e de ter o segundo primário de mama e ovário e podem ser candidatas à retirada das mamas com finalidade de diminuir a chance de desenvolvimento do CM, sendo condutas de exceção em casos muito selecionados. Estima-se que a redução seja de $90 \%$ de risco, posto que nenhuma técnica pode oferecer remoção total de tecido mamário. O objetivo é reduzir o risco oferecendo resultados estéticos muito satisfatório com as técnicas de reconstrução. Recomenda-se que a seleção seja individualizada, com avaliação psicológica e um processo não apressado de tomada de decisão.

Uma outra questáo discutida foi a mastectomia profilática contralateral em mulheres com diagnostico de CM. Destacou que deve avaliar o risco de CM contralateral 
dentro do contexto do prognóstico, idade, comorbidades e avaliação genética. Porem, embora a cirurgia contralateral simultânea tenha demonstrado que pode reduzir a incidência de CM, não tem ainda evidências científicas que melhore a sobrevida.

Por fim, destacou-se a Declaração de Paris, aprovada durante o 2nd International Congress of Breast Disease Centres - Paris, fevereiro de 2012, segundo a qual "Todas mulheres do mundo devem ter acesso a centros equipados, dedicados, certificados em programas de qualidade e que promovam cuidados das doenças das mamas de forma competente e integral", que, sem dúvida, tem melhorado os desfechos do tratamento do CM. Maurício Costa concluiu citando a campanha da Sociedade Internacional de Senologia, da qual é o atual Presidente, que aconselha: "A melhor proteção é sempre o diagnostico oportuno e o mais cedo possível".

\section{Conclusótes}

O câncer de mama está em primeiro lugar entre as neoplasias que acometem as mulheres, felizmente é uma das áreas em que as pesquisas são mais intensas, com boas notícias para o prognóstico das pacientes como demonstrado por Mauricio Costa. As pesquisas têm apontado opçóes terapêuticas que levam a um aumento das taxas de sobrevida global com controle local e sistêmico da doença, com melhora da qualidade de vida das pacientes acometidas pelo câncer de mama.

\section{Conflito DE INTERESSE}

Não há conflito de interesse para esse artigo.

\section{LITERATURA SUGERIDA}

1. Bleicher RJ, Ruth K, Sigurdson ER, Beck JR, Ross E, Wong YN, et al. Time to Surgery and Breast Cancer Survival in the United States. JAMA Oncol. 2016 Mar;2(3):330-9.

2. Instituto Nacional de Câncer Jose Alencar Gomes da Silva. A situação do câncer de mama no Brasil; síntese de dados dos sistemas de informação. Rio de Janeiro, 2019. 85p.

3. Instituto Nacional de Câncer Jose Alencar Gomes da Silva. Estimativa 2020: incidência de câncer no Brasil. Rio de Janeiro, 2019. 120 p. 
4. Jatoi I. Reconsidering axillary surgery for early breast cancer. Indian J Med Res. 2017;145(2):155-157.

5. Simon SD, Bines J, Werutsky G, Nunes JS, Pacheco FC, Segalla JG, et al. Characteristics and prognosis of stage I-III breast cancer subtypes in Brazil:
The AMAZONA retrospective cohort study. Breast. 2019 Apr;44:113-119.

6. Yakoub D, Avisar E, Koru-Sengul T, Miao F, Tannenbaum S, Byrne M, et al. Factors associated with contralateral preventive mastectomy. Breast Cancer (Dove Med Press). 2015;7:1-8. 